\title{
TRANSVERSE FRACTURE OF METACARPAL AND PROXIMAL PHALANGEAL SHAFT FRACTURES OF THE HAND TREATED BY THETA FIXATION
}

\author{
Ashok Ghodke1, Alfven Vieira², Vicky Jain ${ }^{3}$, Rahul Vanjari ${ }^{4}$, Apoorva Dua ${ }^{5}$ \\ ${ }^{1}$ Assistant Professor, Department of Orthopaedics, MGM Medical College and Hospital, Navi Mumbai. \\ ${ }^{2}$ Professor and HOD, Department of Orthopaedics, MGM Medical College and Hospital, Navi Mumbai. \\ ${ }^{3}$ Chief Resident, Department of Orthopaedics, MGM Medical College and Hospital, Navi Mumbai. \\ ${ }^{4}$ Chief Resident, Department of Orthopaedics, MGM Medical College and Hospital, Navi Mumbai. \\ ${ }^{5}$ Senior Resident, Department of Orthopaedics, MGM Medical College and Hospital, Navi Mumbai.
}

\section{ABSTRACT}

\begin{abstract}
BACKGROUND
Many implants and techniques are used for the treatment of transverse metacarpal and phalangeal fractures with varying grades of stability. Simple Kirschner (k) wiring does not provide adequate stability to allow early mobilisation of fingers. Lister described a combination of coronal interosseous wire and oblique $\mathrm{K}$ wire technique for phalangeal and metacarpal fracture fixation with a stable construct that allowed early mobilisation. Due to the fancied resemblance of this construct to the Greek alphabet theta, we have referred to this as theta fixation.
\end{abstract}

\section{MATERIALS AND METHODS}

Twenty-one patients with transverse metacarpal and proximal phalangeal shaft fractures were treated with theta fixation between January and June 2015. Outcome was analysed in terms of stability, early mobilisation, fracture healing and function of the hand. They were graded according to the Belsky score.

\section{RESULTS}

A $90 \%$ patients were graded excellent and $10 \%$ good with one having fair or poor results. All fractures allowed the mobilisation at a mean of 2.9 days and all healed at an average of 6.1 weeks. No loss of stability was seen on followup x-rays. All patients returned to their old profession.

\section{CONCLUSION}

The theta fixation technique is a safe, simple and effective method for transverse metacarpal and proximal phalangeal fractures with results comparable to other techniques. This method gives superior fracture stability to allow early mobilisation of joints and thus early return of function. It is also a cost effective way of management for the developing world.

\section{KEYWORDS}

Metacarpal, Phalanx, Theta Fixation.

HOW TO CITE THIS ARTICLE: Ghodke A, Vieira A, Jain V, et al. Transverse fracture of metacarpal and proximal phalangeal shaft fractures of the hand treated by theta fixation. J. Evolution Med. Dent. Sci. 2016;5(1):82-86, DOI: 10.14260/jemds/2016/19

\section{INTRODUCTION}

Swanson quoted that "The treatment of hand fractures is complicated by deformity from no treatment, stiffness from over treatment and both from poor treatment." This simple but eloquent statement points out the problems associated with phalangeal fracture treatment.

Various methods to treat phalangeal fractures include buddy strapping, percutaneous cross Kirschner (K) wiring, plate fixation and tension band wiring. Transverse metacarpal and phalangeal shaft fractures require internal fixation.

These fractures, however, must be fixed with a minimum of implants to reduce the possibility of infections, but with a stable construct to commence early mobilisation to prevent stiffness.

Financial or Other, Competing Interest: None.

Submission 12-12-2015, Peer Review 14-12-2015,

Acceptance 30-12-2015, Published 04-01-2016.

Corresponding Author:

Dr. Ashok Ghodke,

MGM Medical College and Hospital,

Navi Mumbai.

E-mail: ghodke.ashok@gmail.com

DOI:10.14260/jemds/2016/19
Lister described a technique coronal interosseous wiring with oblique coronal $\mathrm{K}$ wire supplementation for the treatment of phalangeal and metacarpal shaft fractures. ${ }^{1}$

Early mobilisation of phalangeal shaft fracture within the first four weeks after injury resulting in seventy five to eighty percent return of hand function. However, the mobilisation was initiated later than four weeks the hand function was only sixty six percent of pre injury levels.

From this the need of early mobilisation is well understood. Rigid fixation allows early mobilization of the injured digit. Various fixation techniques like single oblique Kwire fixation, plate and screw fixation, etc. have been described for phalangeal shaft fractures. Fyfe and Mason produced experimental fractures of the proximal phalangeal shaft and tested different methods of fixation.

They reported that the least rigid was the single K-wire fixation. Crossed K-wire fixation was more rigid and interosseous wiring supplemented with an oblique K-wire the most rigid. Since this configuration resembles the Greek letter theta, we refer to it as "Theta fixation." The theta fixation therefore can be considered rigid fixation allowing early mobilisation of the fractured digit. 
There is no specific literature available for the outcome of fixation of transverse metacarpal and phalangeal fractures. We report our experience in the management of transverse phalangeal and metacarpal shaft fractures of the hand using the theta fixation technique.

\section{MATERIALS AND METHODS}

Twenty-one patients with transverse fracture of the proximal phalanx and metacarpal from January to June 2015 who underwent fracture fixation using the theta technique after appropriate debridement and wound care were included in this study. The inclusion criteria were (a) single digit transverse proximal phalanx or metacarpal fracture (b) no comorbidities. The exclusion criteria were (a) comminution (b) extensive soft tissue injury (c) patients already with stiffness of any digit.

\section{Operative Procedure}

The fracture was classically approached by a dorsal curvilinear incision (Figure 1a-d). The extensor tendon was retracted to expose the fracture. After trial reduction, two coronal transverse holes were drilled on each fragment parallel to fracture line using $1.25 \mathrm{~mm} \mathrm{~K}$-wire. Stainless steel wire (Gauge 24-26) was threaded through the holes to complete a loop.

The wire was tightened with a wire twister making sure that there was good apposition on the far cortex with a nitchnotch fracture reduction. A K-wire was then drilled obliquely avoiding the drill holes for the steel wires. The K-wire was cut flush with the bone while the steel wire cut and twisted such that the extensor tendon was not impaled in any way (Figure 2a-c).

The free end of the wire loop may also be buried in the bone by a separate drill hole. Closure done. The fingers were immobilised in a volar plaster of Paris slab in the James position.

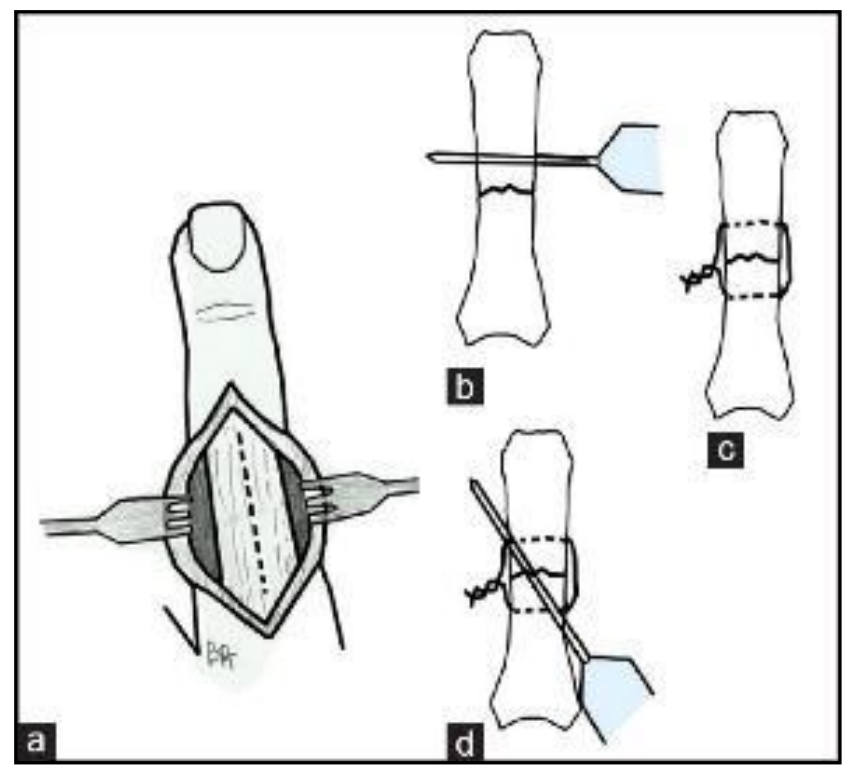

Figure 1

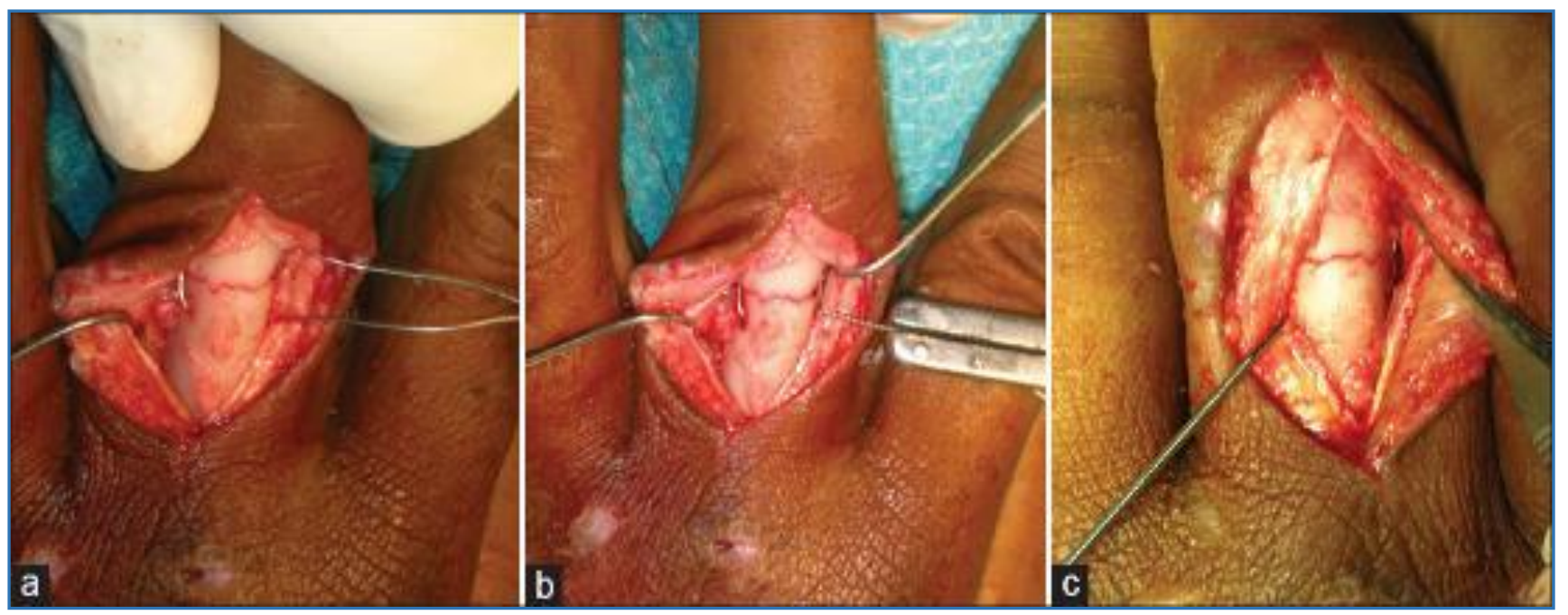

Figure 2

\section{POSTOPERATIVE CARE}

Gentle mobilization of the finger was done by the surgeon during wound inspection and patients were encouraged to move the fingers actively. After the $3^{\text {rd }}$ day, the hand therapist was instructed to commence active and passive mobilization of the hand daily. In order to protect the fixation from unwanted unprotected activity, the splint was continued for 3 weeks.

Patients attended the hand therapy clinic daily where the therapists would remove the splint to encourage active and passive range of motion exercises under supervision and then reapply the splint. The sutures were removed on the $10^{\text {th }}$ day. The slab support to the hand was discontinued at the end of the $3^{\text {rd }}$ week. The K-wires were removed under local anaesthesia in OPD after fracture union if required.

The radiographs were taken on $3^{\text {rd }}$ day, at $6^{\text {th }}$ week and $12^{\text {th }}$ week and $24^{\text {th }}$ week (Figures 3 and 4 ). Patients were allowed to do light work at the end of 6 weeks to return to their profession with full unrestricted activity when radiological evidence of fracture union was confirmed. The outcome was measured by Belsky et al. ${ }^{2}$ score (Table 1 ) at the end of $6^{\text {th }}$ week, $3^{\text {rd }}$ month and $24^{\text {th }}$ month. 


\begin{tabular}{|c|c|}
\hline Belsky Grade & Parameters \\
\hline Excellent & $\begin{array}{r}\text { No symptoms, pain free union, no angular } \\
/ \text { rotational deformity, } \\
\text { PIP }>100^{\circ}, \text { TAM }>250^{\circ}\end{array}$ \\
\hline Good & $\begin{array}{r}\text { Minimal angular } / \text { rotational deformity, } \\
\text { PIP movement of }>80^{\circ}, \text { TAM }>180^{\circ}\end{array}$ \\
\hline Fair & TAM $<180^{\circ}$ \\
\hline Poor & Table 1: The Belsky et al..$^{2}$ score \\
\hline \multicolumn{2}{|c}{} \\
\hline
\end{tabular}

TAM=Total active range of motion, PIP=Proximal interphalangeal
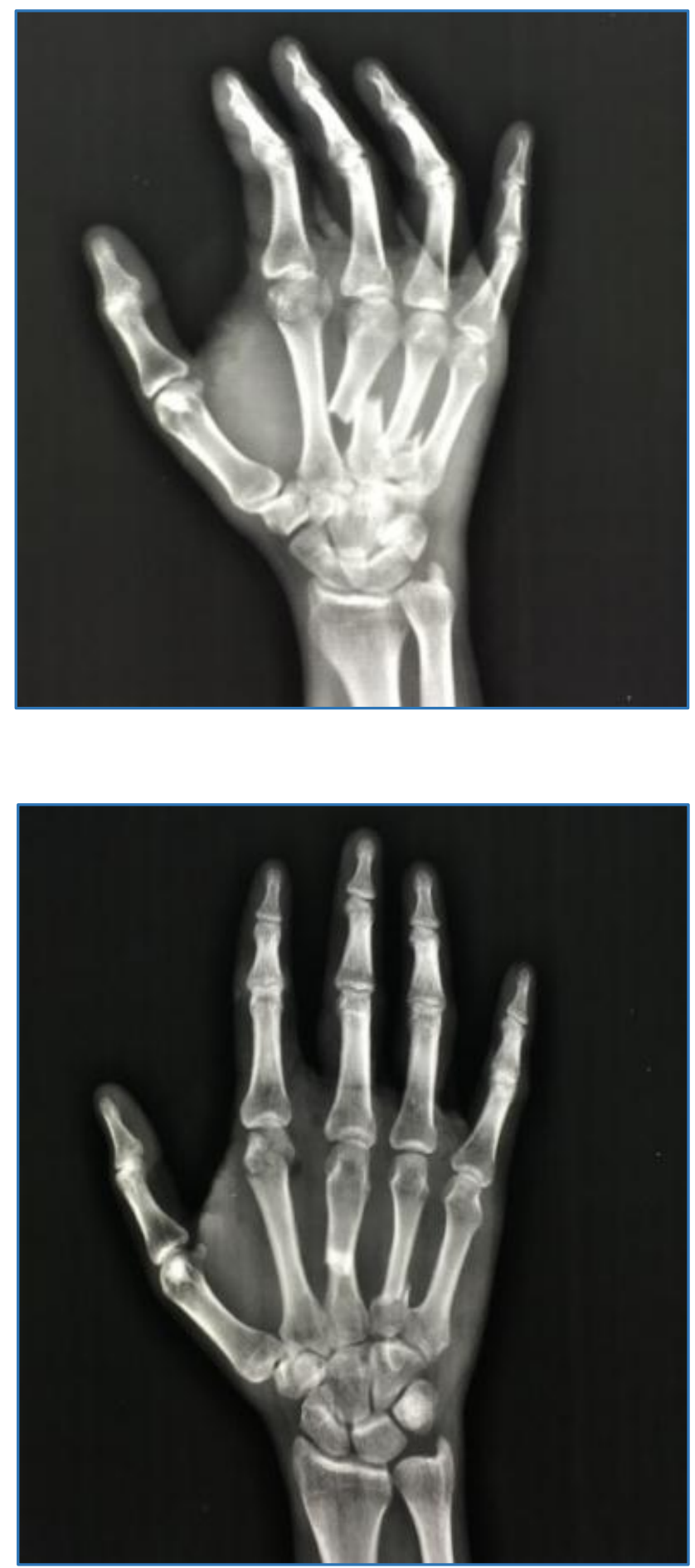

Figure 3

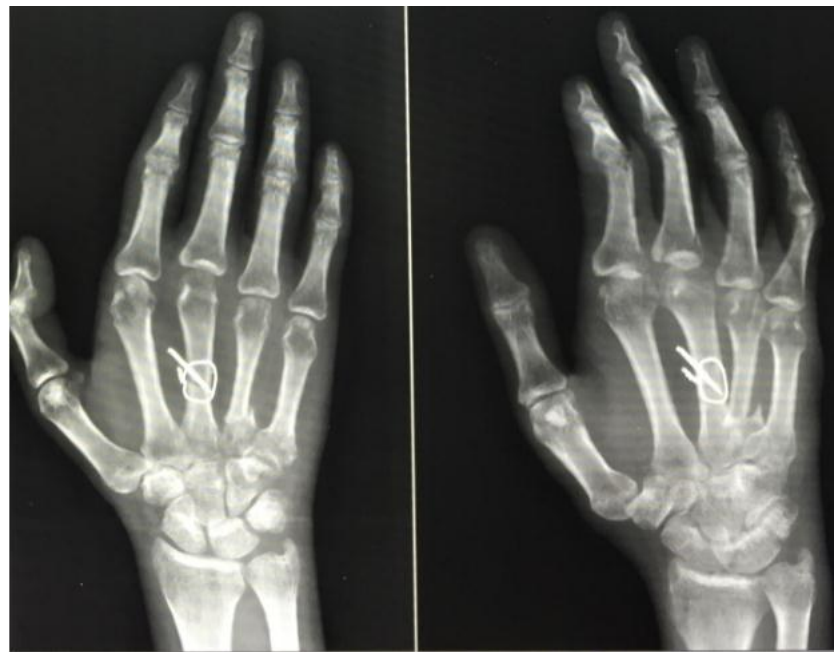

Figure 4

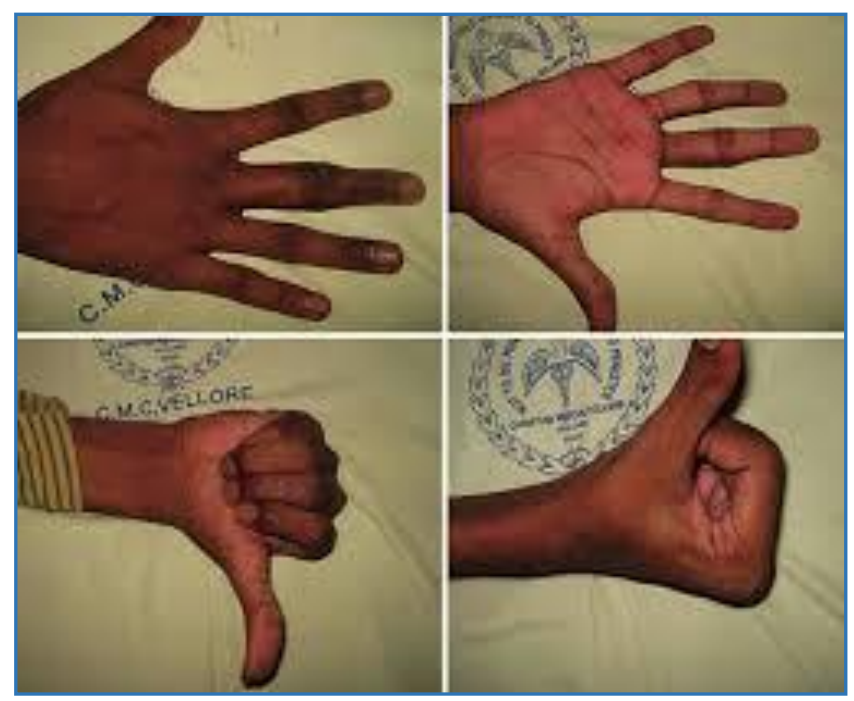

Figure 5

\section{RESULTS}

Of the 21 patients, eighteen were male and three females of which 10 were proximal phalanx fracture and 11 were metacarpal fracture (4-4th metacarpal, 4-3 ${ }^{\text {rd }}$ metacarpal, 3-2 ${ }^{\text {nd }}$ metacarpal) (Table 2). The most common mechanism of injury was road traffic accident $(n=6)$.

The average age was 33.6 years (Range 19-53 years). Index, middle and ring finger were involved in three cases each and thumb in one. The average followup was 28.8 months (Range 25-33 months). The average hospital stay was 5.9 days (Range 5-8 days). The average time for starting mobilization of joints was 2.9 days. The average time to return to unrestricted routine activities and work was 11.3 weeks.

The average duration for radiological healing was 6.1 weeks (Range 6-7 weeks). The outcome by Belsky et al. Scoring method revealed seven excellent and three good results at the end of 6 weeks, which changed to nine excellent and one good at the end of 3 months.

The Digit to Palm Distance (DPD) of all the patients at the end of 6 weeks was zero (Figure 5). No patients had infection or resurgery. Implants were removed in three patients following irritation of the skin by the wire. In one it was done on the patient's request. 


\begin{tabular}{|c|c|c|c|c|c|c|c|}
\hline Sex & $\begin{array}{c}\text { Age } \\
\text { (Years) }\end{array}$ & Side & Finger & $\begin{array}{l}\text { DPD } \\
\text { (cm) }\end{array}$ & $\begin{array}{l}\text { Fracture } \\
\text { Healing } \\
\text { (Weeks) }\end{array}$ & $\begin{array}{c}\text { Follow- } \\
\text { up } \\
\text { (Months) }\end{array}$ & $\begin{array}{l}\text { Hospital Stay } \\
\text { (Days) }\end{array}$ \\
\hline M & 35 & $\mathrm{R}$ & Index & 0 & 6 & 26 & 5 \\
\hline $\mathrm{M}$ & 42 & $\mathrm{R}$ & Ring & 0 & 6 & 29 & 6 \\
\hline M & 46 & $\mathrm{R}$ & Middle & 0 & 6 & 32 & 8 \\
\hline $\mathrm{M}$ & 38 & $\mathrm{~L}$ & Thumb & 0 & 6 & 31 & 7 \\
\hline$M$ & 50 & $\mathrm{~L}$ & Ring & 0 & 6 & 29 & 8 \\
\hline$M$ & 45 & $\mathrm{R}$ & Ring & 0 & 6 & 33 & 5 \\
\hline $\mathrm{M}$ & 33 & $\mathrm{R}$ & Middle & 0 & 6 & 25 & 6 \\
\hline $\mathrm{M}$ & 38 & $\mathrm{R}$ & Little & 0 & 6 & 28 & 6 \\
\hline $\mathrm{M}$ & 43 & $\mathrm{R}$ & Index & 0 & 6 & 27 & 6 \\
\hline $\mathrm{F}$ & 45 & $\mathrm{~L}$ & Ring & 0 & 7 & 26 & 5 \\
\hline $\mathrm{M}$ & 41 & $\mathrm{~L}$ & $4^{\text {th }} \mathrm{MC}$ & 0 & 6 & 29 & 7 \\
\hline $\mathrm{M}$ & 31 & $\mathrm{~L}$ & $3^{\text {rd }} \mathrm{MC}$ & 0 & 6 & 32 & 8 \\
\hline $\mathrm{M}$ & 37 & $\mathrm{~L}$ & $2^{\text {nd }} \mathrm{MC}$ & 0 & 6 & 31 & 8 \\
\hline M & 28 & $\mathrm{R}$ & $3^{\text {rd }} \mathrm{MC}$ & 0 & 6 & 29 & 6 \\
\hline $\mathrm{M}$ & 50 & $\mathrm{~L}$ & $4^{\text {th }} \mathrm{MC}$ & 0 & 6 & 33 & 7 \\
\hline $\mathrm{M}$ & 46 & $\mathrm{R}$ & $2^{\text {nd }} \mathrm{MC}$ & 0 & 7 & 25 & 5 \\
\hline $\mathrm{M}$ & 49 & $\mathrm{R}$ & $2^{\text {nd }} M C$ & 0 & 6 & 28 & 5 \\
\hline $\mathrm{M}$ & 44 & $\mathrm{R}$ & $4^{\text {th }} \mathrm{MC}$ & 0 & 6 & 28 & 6 \\
\hline $\mathrm{M}$ & 39 & $\mathrm{~L}$ & $3^{\text {rd }} \mathrm{MC}$ & 0 & 6 & 27 & 7 \\
\hline $\mathrm{F}$ & 35 & $\mathrm{R}$ & $3^{\text {rd }} \mathrm{MC}$ & 0 & 6 & 26 & 8 \\
\hline $\mathrm{F}$ & 34 & $\mathrm{~L}$ & $4^{\text {th }} \mathrm{MC}$ & 0 & 6 & 29 & 7 \\
\hline \multicolumn{8}{|c|}{ Table 2} \\
\hline
\end{tabular}

\section{DISCUSSION}

Phalangeal fractures are not uncommon injuries. The extensor tendon over the phalangeal shaft may adhere to the fracture site during union causing stiffness of the proximal interphalangeal joint as well as an extensor lag. ${ }^{3}$ Early mobilisation helps in preventing the adhesion.

A rigid fixation is a prerequisite for early mobilization. Transverse phalangeal and metacarpal fractures require internal fixation. Closed reduction and percutaneous cross Kwiring is the standard treatment for closed phalangeal fractures.

However, cross K-wire fixation fails to provide compression at the fracture site especially for transverse shaft fractures. ${ }^{4}$ and may also result in distraction of the fracture with subsequent delayed unions or gap nonunions. ${ }^{5}$ As the construct is not very rigid, early mobilization is not done. Reports on phalangeal fracture fixation generally deal with closed fractures. In this context, the Lister fixation provides adequate stability and early mobilisation.

Lister. ${ }^{1}$ described fixation of transverse fractures and arthrodesis of digits with a cerclage wire and oblique K-wire, which is tension band fixation insisting on obtaining congruous reduction and maintaining fixation till the union. In his series, he had $100 \%$ union rate in the case of transverse fractures.

Overall, $83.2 \%$ of the maximum attainable total active range of motion (TAM) was achieved in the 100 cases. We have been utilizing this technique for the treatment of transverse phalangeal and metacarpal shaft fractures. The theta fixation technique is not as simple as crossed K-wire fixation, has a definite learning curve, but is our fixation of choice for phalangeal and metacarpal shaft fractures when the fracture line is transverse and there is no comminution.

Many studies have shown the efficacy of the tension band technique of fracture fixation. The strength of the K-wire and cerclage wire construct nears that of the plate and screw fixation.
Rayhack et al. ${ }^{6}$ in their study concluded that single looped tension band wires were superior in strength to figure-of-eight constructs in experimental transverse osteotomies. Hung et al. ${ }^{7}$ following biomechanical testing of different fracture fixation techniques in the fifth metatarsal of porcine forelimbs concluded that an intramedullary K-wire and a cerclage interosseous wire was more stable than crossed K-wires, though not as rigid as a dorsal plate and screw fixation.

Pun et al. ${ }^{8}$ reported $70 \%$ fair or poor results in 109 unstable digital fractures treated with K-wire fixations. Lag screw fixation for proximal phalangeal fractures can be done only if the length of the fracture exceeds 2 times the diameter of the bone. ${ }^{9}$

Hence, screw fixation alone is not applicable to a transverse shaft fracture. Page and Stern.10,11 reported total active digital motion was $<180$ degrees in $62 \%$ of fractures after plate fixation of 39 phalangeal fractures. Greene. ${ }^{12-14}$ and Safoury. ${ }^{15}$ have demonstrated that fracture stability is enhanced when the K-wires are supplemented with stainless steel wire, a technique termed composite (Or tension band) wiring.

Massengill et al. ${ }^{16}$ noted that the only construct that is superior in stiffness and strength to any configuration of the wire loop or the K-wires is volar or lateral plate and screw fixation. Gould et al. ${ }^{17}$ concluded that tension band stabilization provides superior strength, stiffness and approximation when compared with K-wire fixation.

Our result is comparable to other studies. ${ }^{18}$ The percutaneous pinning alone was reported to give $83 \%$ excellent result in a study by Hornbach and Cohen. ${ }^{19}$ They reported the results of 12 unstable extra-articular fractures of the proximal phalanx treated with the intramedullary K-wires.

To conclude, theta fixation technique is a safe and effective method for transverse proximal phalangeal and metacarpal shaft fractures. The technique gives good stability and compression at the fracture site, which allows early mobilization of joints to prevent stiffness. 


\section{REFERENCES}

1. Lister G. Intraosseous wiring of the digital skeleton. J Hand Surg Am 1978;3:427-35.

2. Belsky MR, Eaton RG, Lane LB. Closed reduction and internal fixation of proximal phalangeal fractures. J Hand Surg Am 1984;9:725-9.

3. Patankar H, Meman FW. Multiple intramedullary nailing of proximal phalangeal fractures of hand. Indian J Orthop 2008;42:342-6.

4. Freeland AE, Geissler WB, Weiss AP. Surgical treatment of common displaced and unstable fractures of the hand. Instr Course Lect. 2002;51:185-201.

5. Ikuta Y, Tsuge K. Micro bolts and micro-screws for fixation of small bones in the hand. Hand 1974;6:261-5.

6. Rayhack JM, Belsole RJ, Skelton WH, Jr. A strain recording model: analysis of transverse osteotomy fixation in small bones. J Hand Surg Am 1984;9:383-7.

7. Hung LK, So WS, Leung PC. Combined intramedullary Kirschner wire and intra-osseous loop for fixation of finger fractures. J Hand Surg Br 1989;14:171-6.

8. Pun WK, Chow SP, So YC, et al. A prospective study on 284 digital fractures of the hand. J Hand Surg Am. 1989;14:474-81.

9. Steel WM. The A.O. small fragment set in hand fractures. Hand. 1978;10:246-53.

10. Page SM, Stern PJ. Complications and range of motion following plate fixation of metacarpal and phalangeal fractures. J Hand Surg Am. 1998;23:827-32.
11. Stern PJ, Wieser MJ, Reilly DG. Complications of plate fixation in the hand skeleton. Clin Orthop Relat Res. 1987:59-65.

12. Greene T. Open pin fixation of the diaphysis for phalangeal fractures. In: Blair WF, editor. Techniques in Hand Surgery. Baltimore: Williams and Wilkins; 1996, p. 187-91.

13. Greene TL, Noellert RC, Belsole RJ. Treatment of unstable metacarpal and phalangeal fractures with tension band wiring techniques. Clin Orthop Relat Res 1986:78-84.

14. Greene TL, Noellert RC, Belsole RJ, et al. Composite wiring of metacarpal and phalangeal fractures. J Hand Surg Am 1989;14:665-9.

15. Safoury Y. Treatment of phalangeal fractures by tension band wiring. J Hand Surg Br. 2001;26:50-2.

16. Massengill JB, Alexander H, Paron JR, et al. Mechanical analysis of Kirschner wire fixation in a phalangeal model. J Hand Surg Am 1979;4:351-6.

17. Gould WL, Belsole RJ, Skelton WH, Jr. Tension-band stabilization of transverse fractures: an experimental analysis. Plast Reconstr Surg 1984;73:111-6.

18. Al-Qattan MM. Closed reduction and percutaneous Kwires versus open reduction and interosseous loop wires for displaced unstable transverse fractures of the shaft of the proximal phalanx of the fingers in industrial workers. J Hand Surg Eur Vol 2008;33:552-6.

19. Hornbach EE, Cohen MS. Closed reduction and percutaneous pinning of fractures of the proximal phalanx. J Hand Surg Br 2001;26:45-9. 